\title{
COVID-19 leadership challenges in knowledge work
}

\author{
Kirchner, Kathrin; Ipsen, Christine; Hansen, John Paulin
}

Published in:

Knowledge Management Research \& Practice

Link to article, DOI:

10.1080/14778238.2021.1877579

Publication date:

2021

Document Version

Peer reviewed version

Link back to DTU Orbit

Citation (APA):

Kirchner, K., Ipsen, C., \& Hansen, J. P. (2021). COVID-19 leadership challenges in knowledge work. Knowledge Management Research \& Practice, 19(4), 493-500. https://doi.org/10.1080/14778238.2021.1877579

\section{General rights}

Copyright and moral rights for the publications made accessible in the public portal are retained by the authors and/or other copyright owners and it is a condition of accessing publications that users recognise and abide by the legal requirements associated with these rights.

- Users may download and print one copy of any publication from the public portal for the purpose of private study or research.

- You may not further distribute the material or use it for any profit-making activity or commercial gain

- You may freely distribute the URL identifying the publication in the public portal

If you believe that this document breaches copyright please contact us providing details, and we will remove access to the work immediately and investigate your claim 


\section{COVID-19 Leadership Challenges in Knowledge Work}

Considerable attention has been paid to employees' experiences when working from home (WFH) during the COVID-19 pandemic, including their well-being and performance. However, less attention has been paid to how managers experience WFH and how this may challenge them in their new role as distance managers. This study investigates how managers of knowledge work experienced distance management during COVID-19. An international survey was distributed in the first weeks of the Danish national lockdown and collected data from $21^{\text {st }}$ March to $11^{\text {th }}$ May 2020. Based on Danish responses from 1053 employees and 290 managers of knowledge work, who had limited prior experience in distance management, our analysis revealed that managers of knowledge work overall found their work during lockdown more challenging than employees did. The results showed managers to experience the situation significantly differently from employees in 12 central opinions about WFH, in particular regarding the advantage of being able to take breaks at will and the disadvantage of being tied to a computer. A content analysis of the qualitative answers showed that the managers' challenges were directly related to distance management tasks. The implications of this study are that research and practice should consider the wellbeing and performance consequences of working from home not only for employees but also for managers, as their experiences differ, and the managers express challenges in their leadership.

Keywords: managers; knowledge work; working from home; distance management; well-being; COVID-19, challenges

\section{Introduction}

Employees' health, resilience and well-being when working across distances is critical to sustain operations and ensure performance (Poulsen \& Ipsen, 2017). While distance work and management are an integrated part of many jobs (Cropper et al., 2008; Verburg et al., 2013), distance work, dispersed teams and distance management were new experiences for the majority of employees and managers when countries across the world implemented lockdowns due to the COVID-19 pandemic during spring 2020 
(Vargas, 2020). The increasing interest in the effect of working from home (WFH) on employees, their productivity and their well-being during the pandemic has heightened the need to understand how managers should manage and lead across distances to support their employees' mental health and performance (Adenle, 2020; Giurge \& Bohns, 2020; Public Health England, 2020; World Health Organisation, 2020).

Studies on WFH, i.e. telework (Bailey \& Kurland, 2002; Hesketh \& Cooper, 2019; Kurkland \& Bailey, 1999), shows that it has advantages such as flexibility, convenience, autonomy, trust empowerment and increased productivity. However, it may also create a sense of loneliness and feelings of isolation (Hertel et al., 2005; Stich, 2020). Hence WFH comes with both advantages and disadvantages.

The ability to show trust and to empower people is important in distance management to allow employees to perform at their best (Hesketh \& Cooper, 2019; Jones \& Gorell, 2012). Good performance also requires good communication skills the ability to assess needs and create a sense of belonging and proximity, including the ability to adopt different approaches depending on the employee's situation (Hesketh \& Cooper, 2019; Jones \& Gorell, 2012; Poulsen \& Ipsen, 2017).

Knowledge workers' tasks in distributed teams largely consist of processing, sharing and/or creating knowledge and information (Bosch-Sijtsema et al., 2009), so knowledge sharing within an organisation becomes challenging when WFH (van der Lippe \& Lippényi, 2020). Moreover, if knowledge workers cannot work autonomously, are unfamiliar with communication technologies or cannot maintain good social relations with their colleagues, they may be less productive while WFH (Bolisani et al., 2020; Gurstein, 2001; Jackson, 2001).

Knowledge-intensive work is dependent on "human capital" that cannot be managed and controlled like traditional physical capital (Alvesson, 2004); thus, 
knowledge workers must be managed carefully and offered good working conditions and employment conditions (Newell et al., 2009).

During the COVID-19 pandemic, practice and research have generously proposed ideas for how organisations can support their employees in the new ways of working during turbulent times to avoid isolation and support their well-being. While the focus during the COVID-19 pandemic has been on the well-being and performance of employees WFH and their experiences, less attention has been paid to how managers of knowledge work experience WFH compared to employees. As organisations discuss if and how to continue WFH post COVID-19 (Editors note, 2020; Gartner, 2020; The European Commission's Science and Knowledge Centre, 2020), it is fundamental to know how managers experienced the sudden transition to distance management, and what changes will be required for them and their organisation to lead as distance managers.

The aim of this study is to investigate how managers of knowledge work have experienced distance management during COVID-19 compared to employees. The study provides insight into our understanding of the effects of WFH among different organisational actors. The study may contribute to understanding how organisations are to learn from and respond to these experiences, which is key when managers are to implement and lead new ways of working that come with the increase of telework and WFH. This paper offers an insight into the experiences of WFH among Danish managers of knowledge work compared to Danish knowledge workers, and the specific conditions causing these experiences. First, the materials and methods section provides a detailed description of the study. Second, the results are presented, followed by a discussion and conclusion. 


\section{Materials and methods}

We conducted an international online survey including 23 questions covering positive and negative experiences with WFH as well as demographics. We employed a fivepoint Likert scale (from $1=$ strongly disagree to $5=$ strongly agree) but also included questions with nominal answers as well as open questions. An overview of the Likertscaled variables that were included in the study is shown in Table 2.

The Danish government announced a national lockdown on the $11^{\text {th }}$ of March 2020, and kindergartens and primary schools gradually opened beginning in mid-April (Anderson et al., 2015; Statsministeriet, 2020). We collected the Danish data from the $21^{\text {st }}$ of March until the $11^{\text {th }}$ of May, when shopping centres, restaurants, schools for older children and other facilities began to re-open. We distributed the survey via social media platforms and emails. Data were thus collected by non-probabilistic snowball sampling. We did not restrict our data collection to specific companies or branches as all companies were affected by the pandemic situation due to the lockdown.

We applied descriptive statistics as well as t-tests to describe the significant differences between managers and employees. We received answers from 290 Danish managers and 1053 Danish employees, so the total number of answers was 1343. The survey did not distinguish between managers on different management levels. A manager is herein every person who reports to have managerial tasks. Table 1 shows the demographic characteristics of the sample. The majority of answers came from knowledge workers, who can perform their tasks in substantial autonomy, as the majority possessed a university degree. The table shows that managers were a little older than employees, which also contributes to the number of children they have. A $\mathrm{Chi}^{2}$-test revealed a dependence between position as manager/employee and the number 
of children under 15 at home $\left(\mathrm{Chi}^{2}=18.318, \mathrm{p}=.000\right)$, but this correlation is low

(Cramer's V=.117). In addition, managers have a slightly higher level of education.

\section{[INSERT TABLE 1 HERE]}

Table 1. Respondents' overview

To gain insights into the respondents' personal experiences, the survey included the ability to provide additional comments about specific challenges they faced and their experiences of the current situation. We then restricted the analysis of the comments to those that clearly referred to tasks usually performed by managers. Issues that were also mentioned by employees (e.g. taking care of small children, additional home-schooling or longer working hours) were not considered. We conducted a content analysis (Bryman, 2004; Denscombe, 2010, p. 313) of the personal experiences to reveal what the managers portrayed as challenging through their comments. The data were then clustered to order and synthesise them into central topics.

\section{Results}

\section{Comparing managers and employees}

We first conducted a t-test to investigate what distinguishes the situations and perceptions of Danish managers from those of Danish employees. Table 2 gives an overview of all included positive and negative experiences perceived by both managers and employees and lists the significant differences in the results based on the t-test.

\section{[INSERT TABLE 2 HERE]}

Table 2. Variables included in the study, mean values and significant differences between managers and employees based on t-test results 
Both managers and employees feel equally well prepared for WFH, and they try to maintain good relationships with colleagues. However, managers and employees significantly differ in their positive experiences of WFH, as managers agree less that they can avoid long meetings and they can be less flexible. For the negative experiences, managers spend more time on the computer, work longer and perceive their work-life situation and their work as more demanding compared to the employees (see Figure 1).

\section{[INSERT FIGURE 1 HERE]}

Figure 1. Comparison of how employees and managers experience WFH expressed by "Work done compared to normally" vs. "Working hours compared to normally"

Managers are less concerned that they will not have enough work to do from home, and they seem to be better equipped in their home offices. However, both managers and employees would like to see their colleagues more often.

\section{Qualitative analysis of managers' challenges}

Using content analysis (Bryman, 2004), focussing on managers and their specific tasks only, we identified six different challenging issues for Danish managers, which are reported in Table 3.

\section{[INSERT TABLE 3 HERE]}

Table 3. Results of the qualitative analysis of managers' challenges while working from home 
Most managers reported that the main challenges to be "organisation of work" and "communication with the employees". Secondly, leadership from a distance is also considered a challenging task. Work had to be re-organised after the lockdown, projects got delayed, collaboration became more difficult and the direct and informal contact with employees was lost. A major issue is the organisation of the communication and collaboration processes online, where face-to-face communication, including facial expressions and body language, is nearly impossible. Here, video conversation tools were often mentioned as means to mitigate some of the distance-based issues.

\section{Discussion}

This study investigated the impact of WFH on managers of knowledge workers during the COVID-19 pandemic compared to employees' experiences. The analysis shows that WFH has benefits for the employees, such as more flexibility in the working day and less commuting time, but there seem to be more drawbacks to consider for the managers.

\section{WFH is more challenging for managers}

This study found that managers experience WFH to be more challenging than employees (Tables 2 and 3), while both groups consider their work during the pandemic to be more challenging than normal. The data shows that managers worked more hours (i.e. had longer workdays). Possible explanations could be "Additional organisational tasks", "difficulties in leading online" and "coordinating and collaborating with the employees across distance", which the managers reported as challenging experiences when WFH as distance managers.

The data set does not give any insights into the relative increase in hours for either managers or employees. A recent study among 3,143,270 users found that 
compared to pre-pandemic levels, there has been an increase in the number of meetings per person $(+12.9 \%)$ and the number of attendees per meeting $(+13.5 \%)$. The meetings have become shorter, with a decrease in the average length $(-20.1 \%)$. The study concludes that the net effect is that people spent less time in meetings per day $(-11.5 \%)$ in the post-lockdown period. However, the study found a significant and durable increase in length of the average workday $(+8.2 \%$, or +48.5 minutes) (DeFilippis et al., 2020). This may lead people to feel overworked and overwhelmed. If managers WFH work more hours than their employees do, they are potentially at higher risk of stress or burnout due to their working situation.

When leaders experience that their day is getting longer, that there are more meetings and that they tied to computer, then one explanation may be that one of the key activities in management, the informal non-planned chat by the water cooler or coffee machine, is converted into more formal planned meetings online. This may also explain why some managers become less productive even though they work more hours. Another clear challenge mentioned is the "fewer breaks", where the managers experience being more tied to the computer than the employees are. The number of managers' stakeholders can be one explanation of this. If it is more time-consuming to exercise the day-to-day management and at the same time managers are also to coordinate activities with their fellow managers and report to a superior, then more meetings will be held, which does not allow for many breaks. Another possible cause could be the settings of online meetings, which typically follow the default settings of a calendar program. With many stakeholders and meetings, there is a risk that the working day will be tightly packed with meetings without breaks, as the calendar systems do not take time for breaks into account. 


\section{Organisational support for distance managers}

As organisations expect that more people will continue to work from home post COVID-19 (Editors note, 2020; The European Commission's Science and Knowledge Centre, 2020; Vargas, 2020), there is a need to discuss how this should be organised; for example, how to ensure that employees do not overwork or become overwhelmed, that teams perform well and that they have access to the necessary technologies. Further, it is equally important to consider how to support distance managers regarding their performance, well-being and ability to execute across distances and to reduce the challenging conditions for both employees and managers.

We find that organisations should consider how to support distance managers and the processes of distance management and collaboration. Social platforms have already shown their potential in supporting collaboration during the pandemic (Waizenegger et al., 2020). Clear communication between managers and employees, including body language and a common understanding, were often highlighted as important for distance managers in our study. Creative ways should be found to support causal communication and collaboration in a company. Both formal and informal communication can be supported by different social platforms (Razmerita et al., 2014), such as video conferencing systems (to overcome the issue of missing body language) or chat systems, which allow for informal communication. Digital meeting places or virtual reality scenarios may be considered for future socialising (Boughzala et al., 2012; Pearlman \& Gates, 2010), and telerobots are an option for managers who are unable to join physically with their team (Lee \& Takayama, 2011; Tsui et al., 2011). Opportunities for informal communication should also be facilitated to meet with colleagues and discuss what they are working on and how they are feeling. Social platforms can create proximity, help to coordinate, avoid misunderstandings through 
synchronous video communication and thus simplify communication. Organisations should communicate good practices for distance communication that managers can follow and support knowledge sharing among managers. Attention should be given to the possibilities of using social platforms for this purpose (Sarka \& Ipsen, 2017).

\section{Changes in leadership capabilities}

A part of this study was also to focus on what changes would be required from the managers in order to lead across distances. The study shows that core leadership tasks like direct and informal contact and face-to-face communication about work-related tasks, including facial expressions and body language, were nearly impossible. This means that the leaders have had to change their leadership in sync with the changes in task and work processes as they could not lead using the traditional methods when everybody started to work from home. In practice, leadership became a dynamic process that evolved in accordance with who and how many worked from home, and organisations should be aware that leadership is not just about managing people as they used to do. Distance leadership requires change in leadership through learning and adapting to the new ways of working, where the learning process requires activities targeting the managers. Leadership learning results partly from direct feedback and knowledge sharing, as well as from informal coaching and mentoring (Sofo et al., 2013), all of which may be lost when managing from home. Moreover, learning within an organisation is a set of relationships and behaviours that transform tacit into explicit knowledge (Sofo \& Ammirato, 2013). A point that can be made here is that organisational learning (Argyris \& Schön, 1996; Argyris, 1977) becomes more complicated because of the distance, and it is therefore important that organisations create a learning culture (Sofo \& Ammirato, 2013) and find digital ways that create opportunities to learn and develop new leadership capabilities despite the distance. 


\section{Distance management as an organisational responsibility}

Our findings suggest that distance management is both a personal and organisational capability that must be learned and refined. If the focus is solely on single managers and their ability to deal with their tasks, then there is a risk of individual and reactive actions to their situation when they feel challenged. Accordingly, we suggest a shift in focus from viewing the individual as the core of a problem and instead consider the organisational design and capabilities (Galbraith, 2002; Ipsen et al., 2020). For instance, managers might benefit from knowledge sharing with their fellow managers on how to best deal with the new conditions. This sharing should be considered a responsibility of the organisation, for instance via Human Resource initiatives, and not left to the individual manager to deal with. Managers might be provided with a means to organise regular informal gatherings of employees WFH or to establish satellite offices for smaller groups (Nardelli \& Ipsen, 2019).

\section{Distance management of knowledge work—between the positive and negative}

Though managers found WFH more challenging than the employees, it should be noted that the managers also approved of the situation-e.g. shorter meetings and increased work control. This suggests that WFH comes with both advantages and disadvantages to both managers and knowledge workers and that the same aspect of knowledge work constitutes a paradox: the same work-related or organisational issues could be experienced as both an opportunity and a source of stress depending on the role in an organisation.

\section{Conclusion}

The aim of this study was to gain insight into managers' experiences of WFH during 
distance managers in knowledge work. Building on Danish responses from 1053 employees and 290 managers of knowledge work, who had limited prior experience in distance management, our analysis revealed that managers of knowledge work overall found their work during lockdown more challenging than employees did. Their challenges are directly connected to the new work tasks and the loss of social interaction, which emphasises a need to address organisational support to reduce the challenging conditions for both employees and managers. With this in mind, it is important to recognise that becoming a distance manager requires changes in leadership through learning and adapting to the new ways of working where the learning process requires activities targeting the managers - not leaving it up to individual managers to develop new leadership capabilities. In conclusion, it is important that organisations consider the well-being and performance consequences of WFH not only for employees but also for managers, as their experiences differ, and the managers express challenges in their leadership.

\section{Limitations}

There are obvious limitations to this study. First, we only considered Danish data. Managers in other countries might perceive their situations differently depending on, for instance, national differences in the lockdown regulations, their previous experience with WFH, the characteristics of the working culture in their country or the technical infrastructure. Second, the working-from-home situations were clearly influenced by the fact that all family members had to stay at home, so the managers (and employees also) with children or those caring for the elderly might have faced greater challenges. Third, we did not consider the specific company or industrial sector where people are employed. Company culture and organisation might also influence the WFH situation. 
Finally, data were collected in the first weeks of enforced working from home. To address this limitation, we suggest that a follow-up study among managers be conducted. 


\section{References}

Adenle, C. (2020). Working from home during coronavirus? Six tips to make it work. https://www.elsevier.com/connect/working-from-home-during-coronavirus-6-tipsto-make-it-work

Alvesson, M. (2004). Knowledge work and knowledge intensive firms. Oxford University Press.

Anderson, A. J., Kaplan, S. A., \& Vega, R. P. (2015). The impact of telework on emotional experience: When, and for whom, does telework improve daily affective well-being? European Journal of Work and Organizational Psychology, 24(6), 882-897.

Argyris, C. (1977). Double loop learning in organizations. Harvard Business Review. https://hbr.org/1977/09/double-loop-learning-in-organizations

Argyris, C., \& Schön, D. (1996). Organizational learning II. Theory, method and practice. Addison-Wesley Publishing Company.

Bailey, D. E., \& Kurland, N. B. (2002). A review of telework research: findings, new directions, and lessons for the study of modern work. Journal of Organizational Behavior, 23(4), 383-400.

Bolisani, E., Scarso, E., Ipsen, C., Kirchner, K., \& Hansen, J. P. (2020). Working from home during COVID-19 pandemic : Lessons learned and issues. Management \& Marketing. Challenges for the Knowledge Society, 15 (Special Issue), 458-476.

Bosch-Sijtsema, P. M., Ruohomäki, V., \& Vartiainen, M. (2009). Knowledge work productivity in distributed teams. Journal of Knowledge Management, 13(6), 533546.

Boughzala, I., De Vreede, G.-J., \& Limayem, M. (2012). Team collaboration in virtual worlds: Editorial to the special issue. Journal of the Association for Information 
Systems, 13(10), 6-undefined.

Bryman, A. (2004). Social research methods (Vol. 2). Oxford University Press.

Bryman, Alan. (2012). Social research methods (Vol. 4). Oxford University Press.

Cropper, S., Huxham, C., Ebers, M., \& Ring, P. S. (2008). The Oxford handbook of inter-organizational relations (S. Cropper (ed.); 1st ed.). Oxford University Press.

DeFilippis, E., Impink, S., Singell, M., Polzer, J. T., \& Sadun, R. (2020). Collaborating during coronavirus: The impact of COVID-19 on the nature of work. SSRN Electronic Journal.

Denscombe, M. (2010). The good research guide for small scale research projects. Open University Press.

Editors note. (2020). The future of work - is the office finished? | Leaders | The Economist. The Economist. https:/www.economist.com/leaders/2020/09/12/is-theoffice-finished

Galbraith, J. R. (2002). Designing organizations. An executive guide to strategy, structure and process. Jossey-Bass.

Gartner. (2020). Gartner CFO survey reveals 74\% intend to shift some employees to remote work permanently. https://www.gartner.com/en/newsroom/pressreleases/2020-04-03-gartner-cfo-surey-reveals-74-percent-of-organizations-toshift-some-employees-to-remote-work-permanently2

Giurge, L. M., \& Bohns, V. K. (2020). Three tips to avoid WFH burnout. Harvard Business Review. https://hbr.org/2020/04/3-tips-to-avoid-wfh-burnout Gurstein, P. (2001). Wired to the world, chained to the home: Telework in daily life. UBC Press.

Hertel, G., Geister, S., \& Konradt, U. (2005). Managing virtual teams: A review of current empirical research. Human Resource Management Review, 15(1), 69-95. 
Hesketh, I., \& Cooper, C. L. (2019). Wellbeing at work: how to design, implement and evaluate an effective strategy. Kogan Page.

Ipsen, C., Nardelli, G., Edwards, K., \& Kirchner, K. (2020). Sustainable management of job (re)design: A position paper on balancing competitive advantage and organisational performance to ensure healthy workplaces. International Symposium on Human Factors in Organisational Design and Management, 321322.

Jackson, P. J. (2001). Virtual working : social and organisational dynamics. Routledge.

Jones, G., \& Gorell, R. (2012). 50 top tools for coaching : A complete toolkit for developing and empowering people. Kogan Page.

Kurkland, N. B., \& Bailey, D. E. (1999). Telework: The advantages and challenges of working here, there anywhere, and anytime. Organizational Dynamics, 28(2), 5368.

Lee, M. K., \& Takayama, L. (2011). "Now, I have a body": Uses and social norms for mobile remote presence in the workplace. Proceedings of the SIGCHI Conference on Human Factors in Computing Systems, 33-42.

Nardelli, G., \& Ipsen, C. (2019). From co-located to (smart) dispersed work: Digitalising a workplace through commuter hubs. PROS 2019 - Professional Development Workshop.

National Health Service - UK. (2020). Mental wellbeing while staying at home | every mind matters | One You. https://www.nhs.uk/oneyou/every-mindmatters/coronavirus-covid-19-staying-at-home-tips/

Newell S., Robertson M., Scarbrough H., S. J. (2009). Managing knowledge work and innovation. Red Globe Press.

Pearlman, D. M., \& Gates, N. A. (2010). Hosting business meetings and special events 
in virtual worlds: A fad or the future? Journal of Convention and Event Tourism, 11(4), 247-265.

Poulsen, S., \& Ipsen, C. (2017). In times of change: How distance managers can ensure employees' wellbeing and organizational performance. Safety Science, 100, 37-45.

Razmerita, L., Kirchner, K., \& Nabeth, T. (2014). Social media in organizations: Leveraging personal and collective knowledge processes. Journal of Organizational Computing and Electronic Commerce, 24(1), 74-93.

Sarka, P., \& Ipsen, C. (2017). Knowledge sharing via social media in software development: A systematic literature review. Knowledge Management Research and Practice, 15(4), 594-609.

Sofo, F., \& Ammirato, S. (2013). Establishing a learning culture: The importance of relationships within an organization. Communications in Computer and Information Science, 278, 271-277.

Sofo, F., Ammirato, S., \& Sofo, M. (2013). Leadership as a process to create organizational culture and group learning. Organizational Cultures, 12(1), 71-84.

Statsministeriet. (2020, March 11). Pressemøde om COVID-19 den 11. marts 2020. Press Briefing. https://www.stm.dk/presse/pressemoedearkiv/pressemoede-omcovid-19-den-11-marts-2020/

Stich, J.-F. (2020). A review of workplace stress in the virtual office. Intelligent Buildings International, 12(3), 208-220.

The European Commission's Science and Knowledge Centre. (2020). Telework in the EU before and after the COVID-19: Where we were, where we head to. https://ec.europa.eu/jrc/sites/jrcsh/files/jrc120945_policy_brief__covid_and_telework_final.pdf

Tsui, K. M., Desai, M., Yanco, H. A., \& Uhlik, C. (2011). Exploring use cases for 
telepresence robots. 6th ACM/IEEE International Conference on Human-Robot Interaction (HRI). IEEE, 11-18.

van der Lippe, T., \& Lippényi, Z. (2020). Co-workers working from home and individual and team performance. New Technology, Work and Employment, 35(1), $60-79$.

Vargas, O. L. (2020). COVID-19 unleashed the potential for telework - how are workers coping? | Eurofound. Eurofound.

https://www.eurofound.europa.eu/publications/blog/covid-19-unleashed-thepotential-for-telework-how-are-workers-coping

Verburg, R. M., Bosch-Sijtsema, P., \& Vartiainen, M. (2013). Getting it done: Critical success factors for project managers in virtual work settings. International Journal of Project Management, 31(1), 68-79.

Waizenegger, L., McKenna, B., Cai, W., \& Bendz, T. (2020). An affordance perspective of team collaboration and enforced working from home during COVID-19. European Journal of Information Systems, 29(4), 429-442.

World Health Organisation. (2020). \#HealthyAtHome-Mental health. https://www.who.int/news-room/campaigns/connecting-the-world-to-combatCoronavirus/healthyathome/healthyathome---mentalhealth?gclid=Cj0KCQjwn7j2BRDrARIsAHJkxmxB4xRJskiQbYNVuleOnBVwyb yHICVmfR8onLmcTBA5ZPt99T6wLtYaAi4tEALw_wcB 